\title{
BMJ Global Health Behaviour adoption approaches during public health emergencies: implications for the COVID-19 pandemic and beyond
}

\author{
Mohamed F Jalloh (D) , ${ }^{1}$ Aasli A Nur, ${ }^{2}$ Sophia A Nur, ${ }^{1}$ Maike Winters (D) , ${ }^{3}$ \\ Jamie Bedson (D) , ${ }^{4}$ Danielle Pedi, ${ }^{5}$ Dimitri Prybylski, ${ }^{1}$ \\ Apophia Namageyo-Funa (D. , ${ }^{1}$ Kathy M Hageman, ${ }^{1}$ Brian J Baker, ${ }^{1}$ \\ Mohammad B Jalloh, ${ }^{6}$ Eugenia Eng, ${ }^{7}$ Helena Nordenstedt (D) , ${ }^{3}$ Avi J Hakim (D) ${ }^{8}$
}

To cite: Jalloh MF, Nur AA, Nur SA, et al. Behaviour adoption approaches during public health emergencies: implications for the COVID-19 pandemic and beyond. BMJ Global Health 2021;6:e004450. doi:10.1136/ bmjgh-2020-004450

Handling editor Seye Abimbola

- Additional material is published online only. To view, please visit the journal online (http://dx.doi.org/10.1136/ bmjgh-2020-004450).

Received 12 November 2020 Revised 8 January 2021 Accepted 11 January 2021

Check for updates

\section{(c) Author(s) (or their} employer(s)) 2021. Re-use permitted under CC BY-NC. No commercial re-use. See rights and permissions. Published by BMJ.

For numbered affiliations see end of article.

\section{Correspondence to}

Dr Mohamed F Jalloh, Center for Global Health, U.S. Centers for Disease Control and Prevention, Atlanta, Georgia, USA;

yum8@cdc.gov

\section{ABSTRACT}

Human behaviour will continue to play an important role as the world grapples with public health threats. In this paper, we draw from the emerging evidence on behaviour adoption during diverse public health emergencies to develop a framework that contextualises behaviour adoption vis-à-vis a combination of top-down, intermediary and bottom-up approaches. Using the COVID-19 pandemic as a case study, we operationalise the contextual framework to demonstrate how these three approaches differ in terms of their implementation, underlying drivers of action, enforcement, reach and uptake. We illustrate how blended strategies that include all three approaches can help accelerate and sustain protective behaviours that will remain important even when safe and effective vaccines become more widely available. As the world grapples with the COVID-19 pandemic and prepares to respond to (re) emerging public health threats, our contextual framework can inform the design, implementation, tracking and evaluation of comprehensive public health and social measures during health emergencies.

\section{INTRODUCTION}

There is a dynamic relationship between human behaviours and infection transmission during epidemics. ${ }^{1}$ The rise in the number of infections during an epidemic influences the adoption of protective behaviours in the population. Accordingly, the level of adoption of protective behaviours contributes to transmission scenarios and epidemic spread. The COVID-19 pandemic has sparked an unparalleled global discourse around the adoption of protective behaviours and other public health and social measures (PHSMs) to slow the person-to-person spread of SARS-CoV-2. ${ }^{2}$ However, this is not the first or the last time that human behaviour will play an important role during a public health emergency.

\section{Summary box}

- The COVID-19 pandemic has sparked an unparalleled global discourse around the adoption of protective behaviours and other public health and social measures to slow the person-to-person spread of SARS-CoV-2

- However, this is not the first or the last time that human behaviour will play an important role during a public health emergency.

- The effectiveness of implementing critical response strategies, such as contact tracing, diminishes when there is widespread community transmission.

- Using the COVID-19 pandemic as a case study, we developed a framework that contextualises how key protective behaviours (eg, hand hygiene practices, the use of masks and social distancing) can be achieved using (1) top-down, (2) intermediary and (3) bottom-up approaches.

- For each behaviour, we draw examples from a combination of interventions in the COVID-19 response, coupled with other illustrative evidence on behaviour change interventions in routine public health programmes or from past global health emergencies.

- There is no one-size-fits-all approach to get people to perform promoted behaviours during health emergencies.

- Implementing blended strategies that draw from all three approaches might prove to be ideal during health emergencies.

To inform decisions for preparedness, readiness and response activities, the WHO characterises the level of outbreak transmission into four categories based on weekly data, self-reported by the member states: (1) no cases, (2) sporadic cases, (3) clusters of cases and (4) community transmission. ${ }^{3}$ Prompt identification, testing and isolation of suspected cases, along with tracing and quarantining their contacts are effective 
strategies to interrupt person-to-person transmission during infectious disease epidemics, including the COVID-19 pandemic. ${ }^{4-9}$ However, contact tracing is particularly complicated when there are many clusters of cases, ${ }^{10}{ }^{11}$ and the effectiveness of implementing critical response strategies, such as contact tracing, diminishes when there is widespread community transmission. In such a scenario, population-level adoption of protective behaviours is required to limit community transmission, in addition to biomedical interventions, such as vaccines and therapeutics. ${ }^{2}$

In this paper, we draw from the emerging evidence on behaviour adoption during diverse public health emergencies in developing a contextual framework that aims to facilitate a common taxonomy of behaviour adoption approaches. We use the COVID-19 pandemic as an illustrative case study for the application of the contextual framework. As the world grapples with the COVID-19 pandemic and prepares to respond to (re)emerging public health threats, our contextual framework can inform the design, implementation, tracking and evaluation of comprehensive PHSMs and behaviour adoption interventions during health emergencies.

\section{BEHAVIOURAL IMPACT ON INFECTION TRANSMISSION}

The influence of human behaviour on infection transmission has been documented in other public health emergencies prior to the COVID-19 pandemic. ${ }^{12-17}$ The public's voluntary change in avoidance behaviour (eg, spending more time at home) during the 2009 influenza A/H1N1 epidemic in the USA has been measured by combining data on how people spent their time with epidemiological data that accounted for the potential confounding effect of extreme weather conditions. ${ }^{12}$ The findings indicate that voluntary adoption of avoidance behaviours contributed substantially to reducing the attack rate. During the 2003 severe acute respiratory syndrome (SARS) epidemic in Hong Kong, frequent hand washing and increased use of face masks by the general public helped control the epidemic and prevented the flare-up of new clusters. ${ }^{13} 14$ A systematic review showed that frequent hand washing during this epidemic was maintained for 22 months after the initial outbreaks in North America, Mainland China and Hong Kong. ${ }^{18}$ The key behavioural drivers of containing the 2014-2016 Ebola epidemic in Sierra Leone, Liberia and Guinea were population-level improvements in the timeliness of seeking medical care for suspected Ebola cases and avoiding unsafe physical contact with suspected patients with Ebola and bodies during traditional burial practices. ${ }^{15-17} 19$

We have further summarised the drivers of behaviours during past health emergencies (online supplemental material). Despite the differences in sociodemographic settings, the collective evidence demonstrates the need for clear, science-based messaging during infectious disease epidemics to help the public channel anxieties and fears into protective health behaviours, and to build trust in public health measures. This includes effective communication on the current state of knowledge regarding the outbreak, as well as the practical and actionable measures that people can take to mitigate transmission risk. The PHSMs should (1) be informed by behavioural insights data, (2) be coupled with localised two-way interpersonal communication and community engagement approaches that build on existing trusted networks and (3) address community concerns and needs.

\section{CONTEXTUAL FRAMEWORK}

In table 1, we give examples of how key protective behaviours against COVID-19 (eg, hand hygiene practices, the use of face masks and social distancing) can be achieved using (1) top-down, (2) intermediary and (3) bottom-up approaches. For each behaviour, we draw examples from a combination of interventions in the COVID-19 response, coupled with other illustrative evidence on behaviour change interventions in routine public health programmes or from past global health emergencies, including epidemics of Ebola, influenza $\mathrm{A} / \mathrm{H} 1 \mathrm{N1}$ and SARS. We developed a contextual framework to highlight how these three approaches differ considerably in terms of their implementation and underlying drivers of action, as well as enforcement, reach and uptake (figure 1). Effective communication should be a crosscutting feature to enable behaviour adoption in all three approaches. Similarly, transparency and accountability in addressing issues of equity should also be cross-cutting features of all three approaches. ${ }^{20}$

\section{Top-down approaches}

During the COVID-19 pandemic, top-down approaches to achieve behaviour adoption have garnered the most attention, featuring measures such as border closures, school closures and other government-instituted 'lockdowns' that create population-level restriction of movements, in addition to mandates for wearing masks in public spaces. ${ }^{41-24}$ There have been numerous ongoing efforts to track the global implementation of PHSMs since the start of the COVID-19 pandemic. The WHO has developed a harmonised dataset to combine various tracked PHSM data under a common taxonomy. ${ }^{25}$ Our descriptive analysis of the publicly available dataset show that every WHO member state has implemented one or more PHSM and a total of 48795 instances of PHSMs have been documented across 228 countries and territories between January and December 2020. Nearly half of the instances of implemented PHSMs were most closely aligned with top-down approaches related to social and physical distancing measures (table 2).

Emerging evidence suggests that the stringency of topdown PHSMs has partly been a reaction to the sharp increase in new daily cases. ${ }^{26}{ }^{27}$ Low-income countries with limited healthcare systems seemed to have more quickly enacted stricter top-down mitigation policies, 
Table 1 Examples of how to achieve four key protective behaviours against COVID-19, using top-down, intermediary and bottom-up approaches

\begin{tabular}{|c|c|c|}
\hline Behaviour & Top-down approach & Intermediary approach \\
\hline \multirow[t]{3}{*}{$\begin{array}{l}\text { Maintain social } \\
\text { distance and avoid } \\
\text { physical contact }\end{array}$} & $\begin{array}{l}\text { Governments 'lockdown' all } \\
\text { or parts of their countries/ } \\
\text { territories to restrict } \\
\text { movement }\end{array}$ & $\begin{array}{l}\text { Places of worship transition to } \\
\text { outdoor prayer services with } \\
\text { reconfigured seating arrangements }\end{array}$ \\
\hline & $\begin{array}{l}\text { Governments compensate } \\
\text { loss of income due to strict } \\
\text { lockdown measures }\end{array}$ & $\begin{array}{l}\text { Banks implement distancing } \\
\text { markers and restrict the number of } \\
\text { clients entering the building }\end{array}$ \\
\hline & $\begin{array}{l}\text { Fines are issued to people } \\
\text { who violate their home-based } \\
\text { quarantine measures }\end{array}$ & $\begin{array}{l}\text { Retail stores and markets restrict } \\
\text { the number of customers allowed } \\
\text { inside at any given time }\end{array}$ \\
\hline $\begin{array}{l}\text { Wear face masks } \\
\text { in indoor public } \\
\text { places }\end{array}$ & $\begin{array}{l}\text { Governments mandate the } \\
\text { use of face mask in all indoor } \\
\text { public places }\end{array}$ & $\begin{array}{l}\text { Businesses provide face masks to } \\
\text { all staff and customers who do not } \\
\text { have one at the entrance }\end{array}$ \\
\hline
\end{tabular}

Governments mandate the use of face masks on all public transportation

Fines issued to people who violate local face mask ordinances

$\begin{array}{ll}\begin{array}{l}\text { Wash hands } \\ \text { frequently and at } \\ \text { critical points }\end{array} & \begin{array}{l}\text { Governments require } \\ \text { handwashing stations at the } \\ \text { entrance of any establishmen } \\ \text { (eg, restaurants, shops, etc) }\end{array} \\ & \begin{array}{l}\text { Governments institute local } \\ \text { ordinances for mandatory } \\ \text { handwashing in schools' } \\ \text { entry points } \\ \text { Fines are issued to } \\ \text { businesses who violate local } \\ \text { hand hygiene ordinances }\end{array} \\ & \\ \text { Monitor daily } & \text { Governments require } \\ \text { health (signs and } & \begin{array}{l}\text { employers to send home } \\ \text { any staff member exhibiting } \\ \text { symptoms) }\end{array}\end{array}$

Governments institute local ordinances for temperature checks at day-care facilities
Airlines require all crew members and passengers to wear face masks during flights

Non-partisan, non-governmental organisations monitor and help to address misinformation about face masks through online and offline platforms

Restaurants provide handwashing stations and hand disinfectants at the front entrance together with visual messages to remind patrons to practice hand hygiene

Schools incorporate hand hygiene into their health education curriculum

In water scarce settings, public handwashing stations are supported by local businesses as part of their corporate responsibility programmes

\section{Businesses establish guidance for} customers and staff for identifying and acting on symptoms, as well as setting up policies for staff who get sick

Schools incorporate COVID-19safe behaviour education and comprehensive checks at school gates

\section{Bottom-up approach}

Faith leaders incorporate messages on social distancing in their sermons and reference relevant religious texts to support the messages

Community members put up signs at children's playground that read

'Care for each other-Please remember to keep your social distance'

Social media influencers continually engage with their followers to encourage them to practice social distancing as part of their 'new normal' through viral videos

Community members organise a virtual townhall discussion where they collectively agree on wearing a mask when in public places

Peer educators in schools influence classmates on the use of face masks through open and closed social networks

Community members make locally designed masks with special messages to distribute to their neighbours and others in their social networks

\section{In day-care, children learn to sing} special handwashing songs to make it more fun and help them wash for at least $20 \mathrm{~s}$.

Television stations partner with local community groups to develop and share messages on hand hygiene that resonate with local audiences

From social learning and through community engagement, people influence the public to make hand hygiene part of everyday life

Communities develop support mechanisms for quarantined community members

Local school boards consult and engage community to develop guidance and rules for COVID-19safe instruction although for shorter durations and with limited scope. ${ }^{28}$ Early implementation of top-down measures, especially border closures and movement restrictions, may have contributed to slowing transmission in low-income countries coupled with overall reduction in the risk for severe illness and mortality due to having a much younger population than high-income countries. ${ }^{28}$ However, the global easing and lifting of mitigation policies point to 


\begin{tabular}{|c|c|c|c|}
\hline & $\begin{array}{l}\text { TOP-DOWN } \\
\text { APPROACHES }\end{array}$ & $\begin{array}{l}\text { INTERMEDIARY } \\
\text { APPROACHES }\end{array}$ & $\begin{array}{l}\text { BOTTOM-UP } \\
\text { APPROACHES }\end{array}$ \\
\hline & ehaviour adoption & Reinforced behaviour adoption & Voluntary behaviour adopt \\
\hline Strategies & $\begin{array}{l}\text { Laws, mandates, executive } \\
\text { orders, and local ordinances to } \\
\text { mitigate population-level risk }\end{array}$ & $\begin{array}{l}\text { Organisational policies, systems, } \\
\text { and procedures to reinforce the } \\
\text { protective behaviours in specific, } \\
\text { elevated-risk settings }\end{array}$ & $\begin{array}{l}\text { Dialogue, persuasion, role } \\
\text { modelling, and collective action } \\
\text { planning to catalyse voluntary } \\
\text { uptake of protective behaviours }\end{array}$ \\
\hline Driver of action & National and local governments & Institutions and organisations & $\begin{array}{l}\text { Communities, households, and } \\
\text { individuals }\end{array}$ \\
\hline Enforcement & Fines and penalties & Denial of access or service & Self-regulated \\
\hline Key advantages & $\begin{array}{l}\text { Can be quick to implement with } \\
\text { potentially high uptake in the } \\
\text { short-term depending on } \\
\text { enforcement }\end{array}$ & $\begin{array}{l}\text { Low cost and potentially high } \\
\text { uptake in the short- and long-term }\end{array}$ & $\begin{array}{l}\text { Low cost, potentially high } \\
\text { uptake in the short- and long- } \\
\text { term, and trust building }\end{array}$ \\
\hline Key disadvantages & $\begin{array}{l}\text { High cost, sustainability } \\
\text { difficulties, and dependence on } \\
\text { political will and socioeconomic } \\
\text { feasibility }\end{array}$ & $\begin{array}{l}\text { Reliance on institutional will and } \\
\text { capacity to implement }\end{array}$ & $\begin{array}{l}\text { May take long time to } \\
\text { implement, requires high quality } \\
\text { engagement, and can be } \\
\text { difficult to measure direct impact }\end{array}$ \\
\hline
\end{tabular}

Figure 1 Contextualisation of behaviour adoption approaches during public health emergencies.

the difficulty in maintaining such policies, partly due to fatigue and socioeconomic challenges. ${ }^{29}$

Similar to the COVID-19 pandemic, behaviour adoption measures were initially focused on top-down approaches during the 2014-2016 Ebola epidemic in West Africa. ${ }^{30}$ For instance, there were blanket mandates that all deaths (regardless of Ebola status) had to be reported to the governments so that corpses could be buried safely by teams trained in infection prevention and control. ${ }^{31}$ It was mandatory to cremate corpses in the early part of the response in Liberia, causing a major rift between the communities and the government. ${ }^{32}$ In Sierra Leone, burial teams' use of black body bags to transport corpses was perceived as culturally unacceptable by the public. ${ }^{33} 34$ Because of the initial failure of these culturally unacceptable top-down measures, families often refused to report household deaths and chose to secretly bury their loved ones instead of adopting the safe burial process. ${ }^{35}$ Unsafe burials propagated Ebola transmission such that each unsafe burial resulted in an average of three new Ebola cases. ${ }^{36}$ The top-down measures regarding burials had to be rapidly modified to integrate cultural and religious rites in a safe manner. ${ }^{33}$ Eventually, bottom-up community engagement was required to increase and sustain community acceptance of safe burial measures during the Ebola epidemic. ${ }^{37}$

\section{Intermediary approaches}

Intermediary approaches use institutional and organisational policies to reinforce the protective behaviours in elevated risk settings. For example, during the COVID-19 pandemic, the provision of handwashing stations (or alcohol-based hand rubs) at the entrance of restaurants and businesses provides a cue to action for people to practice proper hand hygiene. ${ }^{38}$ In healthcare settings, providing all patients, visitors and service providers with a mask as they enter facilities helps to ensure universal use of masks in these elevated-risk settings. In routine healthcare settings, displaying visual cues that remind providers to wash their hands has been helpful for patients who try to ensure providers' compliance. ${ }^{39}$ Meanwhile, commercial entities (eg, banks) have reconfigured physical spaces in waiting areas to foster appropriate social distancing. ${ }^{40}$

Intermediary approaches may be considered as negotiated forms of behavioural adoption that respect individual's autonomy to weigh their need for access (eg, to banks, schools, places of worship, restaurants, airports, etc) against their willingness to comply with the risk mitigation 
Table 2 Summary of the frequency of public health and social measures implemented by countries and territories between January and December 2020

\begin{tabular}{|c|c|c|c|c|c|c|c|}
\hline PHSM* $^{*}$ & AFR & AMR & EMR & EUR & SEAR & WPR & Total \\
\hline Biological measures & 0 & 1 & 3 & 2 & 1 & 2 & 9 \\
\hline Drug-based measures & 1 & 0 & 0 & 3 & 1 & 1 & 6 \\
\hline Environmental measures & 18 & 21 & 11 & 49 & 4 & 14 & 117 \\
\hline Individual measures & 263 & 722 & 95 & 609 & 106 & 196 & 1991 \\
\hline International travel measures & 1124 & 1206 & 729 & 2074 & 475 & 1225 & 6833 \\
\hline Other measures & 1770 & 4960 & 816 & 4432 & 616 & 1983 & 14577 \\
\hline Communications and engagement & 499 & 1220 & 278 & 996 & 127 & 349 & 3469 \\
\hline Other & 1271 & 3740 & 538 & 3436 & 489 & 1634 & 11108 \\
\hline Social and physical distancing measures & 3054 & 7267 & 1852 & 6318 & 1173 & 2568 & 22232 \\
\hline Domestic travel & 1220 & 2357 & 806 & 1656 & 618 & 871 & 7528 \\
\hline Gatherings, businesses and services & 645 & 1810 & 320 & 1792 & 163 & 585 & 5315 \\
\hline Offices, businesses, institutions and operations & 675 & 1622 & 460 & 1724 & 203 & 652 & 5336 \\
\hline School measures & 441 & 1318 & 234 & 834 & 165 & 398 & 3390 \\
\hline Special populations & 73 & 160 & 32 & 311 & 24 & 62 & 662 \\
\hline Other & 0 & 0 & 0 & 1 & 0 & 0 & 1 \\
\hline Surveillance and response measures & 385 & 1095 & 186 & 775 & 156 & 433 & 3030 \\
\hline Detecting and isolating cases & 241 & 702 & 116 & 519 & 94 & 277 & 1949 \\
\hline Tracing and quarantining contacts & 144 & 393 & 70 & 256 & 62 & 156 & 1081 \\
\hline Grand total & 6615 & 15272 & 3692 & 14262 & 2532 & 6422 & 48795 \\
\hline
\end{tabular}

*Data source: WHO Global Dataset on Tracking of Public Health and Social Measures. Available from: https://www.who.int/emergencies/ diseases/novel-coronavirus-2019/phsm.

AFR, African Region; AMR, Americas Region; EMR, Eastern Mediterranean Region; EUR, European Region; PHSM, public health and social measure; SEAR, South East Asia Region; WPR, Western Pacific Region.

measures to gain access to elevated-risk settings. A major strength of intermediary approaches is their potential to 'nudge' the behaviour via the provision of physical and social cues without needing to always overtly enforce the behaviour to realise high uptake. ${ }^{41}$ Given that intermediary approaches operate across important community institutions, they can be powerful in promoting key protective behaviours and providing continuity of uptake within communities. People may be more willing to calibrate how they should behave based on expectations set by local institutions that they value and trust. Such a negotiated form of behaviour adoption renders the local institutions as important gatekeepers of behaviours in elevated-risk settings. Therefore, in responding to health emergencies, public health entities should partner with and support local institutions with their interpretation and implementation of the available evidence on risk mitigation.

\section{Bottom-up approaches}

Bottom-up approaches facilitate voluntary behaviour adoption through dialogue, persuasion, role-modelling of protective behaviours and collective action planning that include the participation of local communities and households. Voluntary behaviour adoption via bottom-up approaches can be partly explained through psychological constructs, such as social learning and self-efficacy. ${ }^{38}$ Although bottom-up approaches are often facilitated by entities that may be outside of the community, an important feature is the focus on listening to communities, working with them to develop local actions, and including them in the overall public health response. Even without outside facilitation, communities can also independently develop local solutions based on local assets and experiences. It should be noted that bottom-up approaches can take various forms, including the leveraging of social influence and grassroots persuasion principles, even if led by a governmental authority. An example of this during the COVID-19 pandemic is the MaskUp! Campaign spearheaded by a local mayor in Houston, Texas, USA to model the use of facemasks and educate the community on why, when, where and how to use facemasks. ${ }^{42}$ It is also an example of how a top-down measure (mandating of masks by the Texas governor) can be supported through bottom-up approaches (social influence campaign by Houston's mayor).

Moreover, receiving messages framed around the duties and responsibilities to one's family, friends and community may be a promising approach to foster the adoption of protective behaviours during health emergencies. ${ }^{43}$ Tapping into influential people within the social networks 
to communicate a message of duties and responsibilities may help shape community norms regarding the protective behaviours. It has been documented that adolescents might perceive the lack of in-person social interactions as particularly challenging due to public health measures during the COVID-19 pandemic. ${ }^{44}$ The strategic use of social media influencers could be an effective way to foster peer-led outreach among adolescents to promote the uptake of protective behaviours and increased support for testing. In the United Kingdom, the government actively works with social media influencers to promote getting tested for COVID-19, especially among adolescents. $^{45}$

Despite the availability of country-specific examples of bottom-up approaches, the WHO global dataset of PHSMs show that bottom-up approaches have constituted a very small fraction of PHSMs implemented globally during the COVID-19 pandemic. Approximately 7\% of the tracked instances of PHSMs globally were related to communication and public engagement efforts (table 2). It should be noted, however, that the communication and engagement efforts documented in the WHO PHSM dataset have mainly constituted one-way information dissemination efforts via mass media and webbased channels; they were rarely reflective of bottom-up, participatory approaches to engage communities on the protective behaviours. ${ }^{25}$

In other health emergency contexts, community engagement efforts with trusted and influential community members have been used to promote protective behaviours. ${ }^{19}$ For instance, during the 2014-2016 West African Ebola outbreak, large-scale community engagement interventions were implemented by thousands of faith leaders, traditional leaders, influential women leaders and other trusted community members; they worked together to locally interpret top-down measures and ensure that they were appropriate for their communities; then they promoted and modelled the protective behaviours in their communities. ${ }^{19}{ }^{30}$ In Sierra Leone, structured community engagement interventions supported locally owned community action plans that addressed unmet needs for sustained behaviour adoption. ${ }^{3046}$ The emerging evidence from the COVID-19 pandemic, past health emergencies and established theories explaining human behaviour, all point to the need for more innovative, bottom-up approaches that engage trusted community members to communicate the benefits of the protective behaviours and support communities to develop action plans based on their local circumstances, means and strengths.

While bottom-up approaches such as community engagement have suffered from a lack of agreement on broad principles, there have been efforts by UNICEF and global stakeholder to establish technical rigour for such approaches, including the establishment of standards and quality assurance indicators to ensure that 'community engagement is intentional, structured and at the core of sustainable development progress'. ${ }^{47}$ Standards have been developed for the core engagement domains (eg, participation and two-way communication), implementation (eg, planning, monitoring and evaluation), coordination and integration (eg, government leadership and partner coordination) and resource mobilisation (eg, human resources and budgeting). These standards followed on from the Communication for Behavioural Impact (COMBI) toolkit for behavioural and social communication in outbreak response developed by the WHO, UNICEF and global stakeholders. ${ }^{48}$ COMBI stresses that 'each outbreak is unique, and community understanding of diseases and their spread is complex, context dependent, and culturally-mediated'.

\section{THE NEED FOR BLENDED APPROACHES AND EFFECTIVE COMMUNICATION}

There is no one-size-fits-all approach to encourage and support promoted behaviours during health emergencies. $^{48}$ Implementing blended strategies that draw from all three approaches might prove to be ideal. A prime example of how a blended approach can be achieved is Taiwan's open consultation platform (vTaiwan); it brought together stakeholders (using online and offline platforms) from the government, civil society and private sector to propose, discuss, reflect and legislate; this platform had been in use for a range of issues prior to COVID-19. ${ }^{42}$ Such an approach could also be leveraged for responding to COVID-19 and illuminates the potential for innovative thinking to blend all three approaches into a unified platform to facilitate collective action. Effective communication should be an important feature across all approaches, especially in the context of the complexities posed by emerging 'infodemic' fuelled by fake news and misinformation campaigns. ${ }^{49}$ It is critical to have ongoing and credible communication to inform the public about what is known (and unknown) to gain and sustain the public's confidence in the emergency response while responding to the infodemic at the same time; this would enable the public to effectively make decisions on how to best protect themselves, their families and their communities. ${ }^{50}$

\section{SUSTAINABILITY AND SPILL-OVER EFFECTS}

While all three approaches may be necessary for optimal behaviour adoption, there is evidence suggesting that bottom-up approaches may be more effective in sustaining the protective behaviours over long term. ${ }^{51}$ Laying a solid foundation for voluntary behaviour change and community action through bottom-up approaches of community engagement may also strengthen social cohesion and build the trust needed to enhance adherence to top-down mitigation measures, especially in the context of community spread of infection during an outbreak. Bottom-up approaches also offer the flexibility and durability required to adapt to changes in the epidemiology and/or in the new knowledge about transmission dynamics. Sustained adoption of protective behaviours 
could also have positive spill-over effects on other health outcomes. During past cholera outbreaks, the widespread use of oral rehydration therapy for suspected cholera cases helped to reduce deaths caused by other diarrhoeal diseases. ${ }^{52}$ Voluntary hand washing during the COVID-19 pandemic can similarly help to reduce the burden of diarrhoeal diseases and other respiratory illnesses such as influenza.

More broadly, the public trust built in the process of implementing and supporting bottom-up approaches that engage communities during the COVID-19 pandemic may also provide a much-needed foundation for promoting the uptake of COVID-19 vaccines as they become more widely available over time. Insights gleaned from past vaccination strategies, including the use of experimental vaccines during Ebola outbreaks, have taught us some important lessons. Ebola vaccine acceptance among health workers and the general public in Guinea, Sierra Leone, Liberia and the Democratic Republic of Congo were driven by complex factors, including perceptions around safety and effectiveness, ${ }^{53}$ institutional trust, ${ }^{54}$ notions of fairness and equity ${ }^{55}$ and subjective norms. ${ }^{56}$ Similar to the introduction of new Ebola vaccines, emerging evidence regarding intentions to accept COVID-19 vaccines point to potential hurdles in attaining optimal uptake among the general public $^{57} 58$ and health workers. ${ }^{59}$ Getting ahead of the curve in addressing misinformation and concerns regarding COVID-19 vaccines can be greatly enhanced through well planned, bottom-up engagements with communities, using online and offline platforms on an ongoing basis.

\section{OPTIMISING SUSTAINABLE BEHAVIOUR ADOPTION}

Although all three approaches have distinct and important roles that are mutually reinforcing, the global COVID-19 response efforts have heavily focused on topdown approaches and some intermediary approaches. Bottom-up approaches have received less attention but offer a powerful pathway to achieve and sustain protective behaviours during the pandemic. Applying the reviewed evidence to our contextual framework suggests that bottom-up approaches that facilitate sustained community engagement should be fostered and maintained throughout all stages of the health emergency. Intermediary approaches, leveraging reinforcement and nudging for positive behaviours need to be targeted in elevated-risk settings (eg, indoor spaces with potential for crowding and close contact). Top-down mitigation measures need to be selectively considered depending on dynamics of community transmission, burden on hospital resources and the healthcare system, access to essential health and social services and other factors. If pursued, the timing and duration of the mandated behaviour must be carefully weighed to optimise the potential positive effects on disrupting unmitigated spread, while minimising the potential negative effects on economies, other healthcare and social well-being in the short and long term.

Human behaviours during health emergencies are intertwined with the cultural realities and sociopolitical climate of the society as people try make sense of their situation and respond to perceived threats. The feasibility and magnitude of success in implementing any behaviour adoption approaches are likely to be influenced by underlying cultural and sociopolitical predispositions that vary across place and time. ${ }^{60-64}$ Relatedly, there are ongoing debates regarding the differences in the ability of authoritarian versus democratic governments in implementing top-down mitigation measures in responding to the COVID-19 pandemic. ${ }^{65-67}$ The collective evidence suggests that behavioural interventions aiming to curb infection transmission during health emergencies, including in the COVID-19 pandemic, need to take into account the complex cultural and sociopolitical factors that influence behavioural uptake.

\section{CONCLUSIONS}

Bottom-up approaches to achieve behaviour adoption are often treated as an after-thought or the 'spare tire' during health emergencies and are perceived as time and resource intensive. When top-down measures fail to produce the desired results in behaviour change, that is usually when more attention gravitates to the bottom-up approaches, which increases the overall time invested for behaviour change and supporting community action. Ideally, bottom-up approaches should be one of the four main tires of the vehicle driving the response; in some instances, they may need to be the steering wheel. Protective behaviours can also be strongly reinforced through intermediary approaches when responsive institutional policies to mitigate transmission risk are well supported. Blended approaches that include intermediary and bottom-up measures for catalysing behaviour adoption should be considered more broadly in order to help slow the current pandemic while we wait for COVID-19 vaccines to become more widely available to the public. Even after safe and effective COVID-19 vaccines become more widely available, the implementation of bottom-up community engagement will be paramount for achieving optimal vaccination uptake and the maintenance of other protective behaviours.

\footnotetext{
Author affiliations

${ }^{1}$ Center for Global Health, Centers for Disease Control and Prevention, Atlanta, Georgia, USA

${ }^{2}$ Department of Sociology, University of Washington, Seattle, Washington, USA ${ }^{3}$ Department of Global Public Health, Karolinska Institutet, Stockholm, Sweden ${ }^{4}$ Independent Consultant, Seattle, Washington, USA

${ }^{5}$ Bill and Melinda Gates Foundation, Seattle, Washington, USA

${ }^{6}$ Focus 1000 , Freetown, Sierra Leone

${ }^{7}$ Gillings School of Global Public Health, University of North Carolina, Chapel Hill, North Carolina, USA

${ }^{8}$ CDC COVID-19 Response Team, Atlanta, Georgia, USA
} 
Acknowledgements We thank the following colleagues for reviewing and providing feedback on the manuscript: Dr Barbara Marston, Dr Abigail Shefer and Dr Wangeci Gatei.

Contributors MFJ, SAN and AAN initially conceptualised the contextual framework, which was refined through multiple rounds of feedback from all authors. MFJ and AAN conducted the initial literature review, which was expanded by contributions from $\mathrm{AH}, \mathrm{MW}, \mathrm{JB}, \mathrm{HN}$ and EE. MFJ drafted the initial manuscript. All authors contributed substantially to the writing of the manuscript. All authors approved the final version of the submitted manuscript.

Funding The authors have not declared a specific grant for this research from any funding agency in the public, commercial or not-for-profit sectors.

Disclaimer The findings and conclusions in this report are those of the authors and do not necessarily represent the official position of the U.S. Centers for Disease Control and Prevention or any institutions they are affiliated with.

Competing interests None declared.

Patient consent for publication Not required.

Provenance and peer review Not commissioned; externally peer reviewed.

Data availability statement Data are available in a public, open access repository.

Supplemental material This content has been supplied by the author(s). It has not been vetted by BMJ Publishing Group Limited (BMJ) and may not have been peer-reviewed. Any opinions or recommendations discussed are solely those of the author(s) and are not endorsed by BMJ. BMJ disclaims all liability and responsibility arising from any reliance placed on the content. Where the content includes any translated material, BMJ does not warrant the accuracy and reliability of the translations (including but not limited to local regulations, clinical guidelines, terminology, drug names and drug dosages), and is not responsible for any error and/or omissions arising from translation and adaptation or otherwise.

Open access This is an open access article distributed in accordance with the Creative Commons Attribution Non Commercial (CC BY-NC 4.0) license, which permits others to distribute, remix, adapt, build upon this work non-commercially, and license their derivative works on different terms, provided the original work is properly cited, appropriate credit is given, any changes made indicated, and the use is non-commercial. See: http://creativecommons.org/licenses/by-nc/4.0/.

\section{ORCID iDs}

Mohamed F Jalloh http://orcid.org/0000-0002-7206-8042

Maike Winters http://orcid.org/0000-0003-0915-6506

Jamie Bedson http://orcid.org/0000-0003-4419-9536

Apophia Namageyo-Funa http://orcid.org/0000-0002-6758-021X

Helena Nordenstedt http://orcid.org/0000-0002-9226-6441

Avi J Hakim http://orcid.org/0000-0001-6754-6241

\section{REFERENCES}

1 Poletti P, Caprile B, Ajelli M, et al. Spontaneous behavioural changes in response to epidemics. J Theor Biol 2009;260:31-40.

2 West R, Michie S, Rubin GJ, et al. Applying principles of behaviour change to reduce SARS-CoV-2 transmission. Nat Hum Behav 2020;4:451-9.

3 World Health Organization. Coronavirus disease (COVID-19) technical guidance: surveillance and case definitions, 2020. Available: https://www.who.int/emergencies/diseases/novelcoronavirus-2019/technical-guidance/surveillance-and-casedefinitions [Accessed 15 Apr 2020].

4 Kucharski AJ, Klepac P, Conlan AJK, et al. Effectiveness of isolation, testing, contact tracing, and physical distancing on reducing transmission of SARS-CoV-2 in different settings: a mathematical modelling study. Lancet Infect Dis 2020;20:1151-60.

5 Hellewell J, Abbott S, Gimma A, et al. Feasibility of controlling COVID-19 outbreaks by isolation of cases and contacts. Lancet Glob Health 2020;8:e488-96.

6 Lau H, Khosrawipour V, Kocbach P, et al. The positive impact of lockdown in Wuhan on containing the COVID-19 outbreak in China. $J$ Travel Med 2020;27. doi:10.1093/jtm/taaa037. [Epub ahead of print: 1805 2020]

7 Crook P, Smith-Palmer A, Maguire $\mathrm{H}$, et al. Lack of secondary transmission of Ebola virus from healthcare worker to 238 contacts, United Kingdom, December 2014. Emerg Infect Dis 2017;23:2081-4.
8 Desclaux A, Ndione AG, Badji D, et al. [Ebola contacts' surveillance: social impact and ethical issues in Senegal]. Bull Soc Pathol Exot 2016;109:296-302

9 Francesconi P, Yoti Z, Declich S, et al. Ebola hemorrhagic fever transmission and risk factors of contacts, Uganda. Emerg Infect Dis 2003;9:1430-7.

10 Greiner AL, Angelo KM, McCollum AM, et al. Addressing contact tracing challenges-critical to halting Ebola virus disease transmission. Int J Infect Dis 2015:41:53-5.

11 Senga M, Koi A, Moses L, et al. Contact tracing performance during the Ebola virus disease outbreak in Kenema district, Sierra Leone. Philos Trans R Soc Lond B Biol Sci 2017;372. doi:10.1098/ rstb.2016.0300. [Epub ahead of print: 26 May 2017].

12 Bayham J, Kuminoff NV, Gunn Q, et al. Measured voluntary avoidance behaviour during the $2009 \mathrm{~A} / \mathrm{H} 1 \mathrm{~N} 1$ epidemic. Proc Biol Sci 2015;282:20150814.

13 Leung GM, Lam T-H, Ho L-M, et al. The impact of community psychological responses on outbreak control for severe acute respiratory syndrome in Hong Kong. J Epidemiol Community Health 2003;57:857-63.

14 Lau JTF, Yang $\mathrm{X}$, Tsui $\mathrm{H}$, et al. Monitoring community responses to the SARS epidemic in Hong Kong: from day 10 to day 62. J Epidemiol Community Health 2003;57:864-70.

15 Fast SM, Mekaru S, Brownstein JS, et al. The role of social mobilization in controlling Ebola virus in Lofa County, Liberia. PLoS Curr 2015;7. doi:10.1371/currents.outbreaks. c3576278c66b22ab54a25e122fcdbec1. [Epub ahead of print: 15 May 2015].

16 Funk S, Ciglenecki I, Tiffany A, et al. The impact of control strategies and behavioural changes on the elimination of Ebola from Lofa County, Liberia. Philos Trans $R$ Soc Lond B Biol Sci 2017;372. doi:10.1098/rstb.2016.0302. [Epub ahead of print: 26 May 2017].

17 Jalloh MF, Sengeh P, Bunnell RE, et al. Evidence of behaviour change during an Ebola virus disease outbreak, Sierra Leone. Bull World Health Organ 2020;98:330-40.

18 Fung IC-H, Cairncross S. How often do you wash your hands? A review of studies of hand-washing practices in the community during and after the SARS outbreak in 2003. Int $J$ Environ Health Res 2007;17:161-83.

19 Gilmore B, Ndejjo R, Tchetchia A, et al. Community engagement for COVID-19 prevention and control: a rapid evidence synthesis. BMJ Glob Health 2020;5:e003188.

20 Weinick RM, Hasnain-Wynia R. Quality improvement efforts under health reform: how to ensure that they help reduce disparities-not increase them. Health Aff 2011;30:1837-43.

21 Wang $\mathrm{Y}$, Tian $\mathrm{H}$, Zhang $\mathrm{L}$, et al. Reduction of secondary transmission of SARS-CoV-2 in households by face mask use, disinfection and social distancing: a cohort study in Beijing, China. BMJ Glob Health 2020;5:e002794.

22 Roques L, Klein EK, Papaïx J, et al. Impact of Lockdown on the epidemic dynamics of COVID-19 in France. Front Med 2020;7:274.

23 Goscé L, Phillips PA, Spinola P, et al. Modelling SARS-COV2 spread in London: approaches to lift the Lockdown. J Infect 2020;81:260-5.

24 Jarvis Cl, Van Zandvoort K, Gimma A, et al. Quantifying the impact of physical distance measures on the transmission of COVID-19 in the UK. BMC Med 2020;18:124.

25 World Health Organization. Tracking public health and social measures: global Databaset, 2020. Available: https://www.who.int/ emergencies/diseases/novel-coronavirus-2019/phsm [Accessed 5 Jan 2021].

26 Oxford. Coronavirus government response tracker, 2020. Available: https://www.bsg.ox.ac.uk/research/research-projects/coronavirusgovernment-response-tracker [Accessed 1 Aug 2020]

27 Oxford. Variation in government responses to COVID-19, 2020. Available: https://www.bsg.ox.ac.uk/sites/default/files/2020-05/ BSG-WP-2020-032-v6.0.pdf [Accessed 1 Aug 2020].

28 Walker PGT, Whittaker C, Watson OJ, et al. The impact of COVID-19 and strategies for mitigation and suppression in low- and middleincome countries. Science 2020;369:413-22.

29 Kachanoff FJ, Bigman YE, Kapsaskis K, et al. Measuring realistic and symbolic threats of COVID-19 and their unique impacts on well-being and adherence to public health behaviors. Soc Psychol Personal Sci 2020:194855062093163.

30 Bedson J, Jalloh MF, Pedi D, et al. Community engagement in outbreak response: lessons from the 2014-2016 Ebola outbreak in Sierra Leone. BMJ Glob Health 2020;5:e002145.

31 Nielsen CF, Kidd S, Sillah ARM, et al. Improving burial practices and cemetery management during an Ebola virus disease epidemic Sierra Leone, 2014. MMWR Morb Mortal Wkly Rep 2015;64:20-7. 
32 Time Magazine. Liberia burns its bodies as Ebola fears run rampant, 2014. Available: https://time.com/3478238/ebola-liberia-burialscremation-burned/ [Accessed 20 Aug 2020].

33 Blevins JB, Jalloh MF, Robinson DA. Faith and global health practice in Ebola and HIV emergencies. Am J Public Health 2019;109:379-84.

34 Nuriddin A, Jalloh MF, Meyer E, et al. Trust, fear, stigma and disruptions: community perceptions and experiences during periods of low but ongoing transmission of Ebola virus disease in Sierra Leone, 2015. BMJ Glob Health 2018;3:e000410.

35 Lee-Kwan SH, DeLuca N, Bunnell R, et al. Facilitators and barriers to community acceptance of safe, Dignified medical Burials in the context of an Ebola epidemic, Sierra Leone, 2014. J Health Commun 2017;22:24-30.

36 Tiffany A, Dalziel BD, Kagume Njenge $\mathrm{H}$, et al. Estimating the number of secondary Ebola cases resulting from an unsafe burial and risk factors for transmission during the West Africa Ebola epidemic. PLoS Negl Trop Dis 2017;11:e0005491.

37 Pedi D, Gillespie A, Bedson J, et al. The development of standard operating procedures for social mobilization and community engagement in Sierra Leone during the West Africa Ebola outbreak of 2014-2015. J Health Commun 2017;22:39-50.

38 ed.Glanz KR, B.K.; Viswanath K. Health beahvior: theory, research, and practice. Fifth edition. San Francisco, California: Jossey-Bass, 2015.

39 Ahmed Awaji M, Al-Surimi K. Promoting the role of patients in improving hand hygiene compliance amongst health care workers. BMJ Qual Improv Rep 2016;5. doi:10.1136/bmjquality.u210787. w4336. [Epub ahead of print: 0807 2016].

40 HSBC HongKong. COVID-19 measures, 2020. Available: https:// www.hsbc.com.hk/help/coronavirus/ [Accessed 25 Aug 2020].

41 Ledderer L, Kjær M, Madsen EK, et al. Nudging in public health lifestyle interventions: a systematic literature review and Metasynthesis. Health Educ Behav 2020;47:749-64.

42 Houston. MASK UP! Campaign, 2020. Available: http://www. houstontx.gov/mask-up.html [Accessed 22 Aug 2020].

43 Everett J, Chituc C; Brady V;. The effectiveness of moral messages on public health behavioral intentions during the COVID-19 pandemic. PsyArXiv Preprints 2020.

44 Andrews JL, Foulkes L, Blakemore S-J. Peer influence in adolescence: public-health implications for COVID-19. Trends Cogn Sci 2020;24:585-7.

45 The Conversation. Why the UK government is paying social media influencers to post about coronavirus, 2020. Available: https:// theconversation.com/why-the-uk-government-is-paying-socialmedia-influencers-to-post-about-coronavirus-145478 [Accessed Sep 2020]

46 Skrip LA, Bedson J, Abramowitz S, et al. Unmet needs and behaviour during the Ebola response in Sierra Leone: a retrospective, mixed-methods analysis of community feedback from the social mobilization action Consortium. Lancet Planet Health 2020;4:e74-85.

47 UNICEF. Minimum quality Standards and indicators in community engagement, 2020. Available: https://www.unicef.org/mena/reports/ community-engagement-standards [Accessed 1 Aug 2020].

48 World Health Organization. Communication for behavioural impact (COMBI): a toolkit for behavioural and social communication in outbreak response, 2012. Available: https://www.who.int/ihr/ publications/combi toolkit_outbreaks/en/ [Accessed 19 Sep 2020].
49 The Lancet Infectious Diseases. The COVID-19 infodemic. Lancet Infect Dis 2020;20:875.

50 United States Centers for Disease Control and Prevention. Crisis \& Emergency Risk Communication (CERC) Manual, 2014. Available: https://emergency.cdc.gov/cerc/manual/index.asp [Accessed 20 Sep 2020].

51 Marathe A, Lewis B, Barrett C, et al. Comparing effectiveness of topdown and bottom-up strategies in containing influenza. PLoS One 2011;6:e25149.

52 Tappero JW, Tauxe RV. Lessons learned during public health response to cholera epidemic in Haiti and the Dominican Republic. Emerg Infect Dis 2011;17:2087-93.

53 Jalloh MF, Jalloh MB, Albert A, et al. Perceptions and acceptability of an experimental Ebola vaccine among health care workers, frontline staff, and the general public during the 2014-2015 Ebola outbreak in Sierra Leone. Vaccine 2019;37:1495-502.

54 Vinck P, Pham PN, Bindu KK, et al. Institutional trust and misinformation in the response to the 2018-19 Ebola outbreak in North Kivu, DR Congo: a population-based survey. Lancet Infect Dis 2019;19:529-36.

55 Enria L, Lees S, Smout E, et al. Power, Fairness and trust: understanding and engaging with vaccine trial participants and communities in the setting up the EBOVAC-Salone vaccine trial in Sierra Leone. BMC Public Health 2016;16:1140.

56 Jalloh MF, Wallace AS, Bunnell RE, et al. Ebola vaccine? family first! evidence from using a brief measure on Ebola vaccine demand in a national household survey during the outbreak in Sierra Leone. Vaccine 2020;38:3854-61.

57 Malik AA, McFadden SM, Elharake J, et al. Determinants of COVID-19 vaccine acceptance in the US. EClinicalMedicine 2020;26:100495.

58 Wong LP, Alias H, Wong P-F, et al. The use of the health belief model to assess predictors of intent to receive the COVID-19 vaccine and willingness to pay. Hum Vaccin Immunother 2020;16:1-11.

59 Papagiannis D, Malli F, Raptis DG, et al. Assessment of knowledge attitudes, and practices towards new coronavirus (SARS-CoV-2) of health care professionals in Greece before the outbreak period. Int J Environ Res Public Health 2020;17. doi:10.3390/ijerph17144925. [Epub ahead of print: 0807 2020].

60 Friedler A. Sociocultural, behavioural and political factors shaping the COVID-19 pandemic: the need for a biocultural approach to understanding pandemics and (re)emerging pathogens. Glob Public Health 2021;16:17-35.

61 Leatherman T, Goodman A. Building on the biocultural syntheses: 20 years and still expanding. Am J Hum Biol 2020;32:e23360.

62 Poleykett B. Ethnohistory and the dead: cultures of colonial epidemiology. Med Anthropol 2018;37:472-85.

63 Klain R. Politics and pandemics. N Engl J Med 2018;379:2191-3.

64 Grossman G, Kim S, Rexer JM, et al. Political partisanship influences behavioral responses to governors' recommendations for COVID-19 prevention in the United States. Proc Natl Acad Sci U S A 2020;117:24144-53.

65 Greer SL, King EJ, da Fonseca EM, et al. The comparative politics of COVID-19: the need to understand government responses. Glob Public Health 2020;15:1413-6.

66 Alon I, Farrell M, Li S. Regime type and COVID-19 response. FIIB Business Review 2020;9:152-60.

67 Kavanagh MM. Authoritarianism, outbreaks, and information politics. Lancet Public Health 2020;5:e135-6. 